\title{
New Inhibitors of the P38 Mitogen-Activated Protein Kinase: Repurposing Existing Drugs with Deep Learning
}

\author{
Aakarsh Vermani ${ }^{1}$, Valentina L. Kouznetsova ${ }^{2,3}$, Igor F. Tsigelny ${ }^{2,3,4, * \text { (D) }}$ \\ REHS program, San Diego Supercomputer Center, UC San Diego, Calif., USA \\ San Diego Supercomputer Center, UC San Diego, Calif., USA \\ BiAna, San Diego, Calif., USA \\ 4 Dept. of Neurosciences, UC San Diego, Calif., USA \\ * Correspondence to: itsigeln@ucsd.edu (I.F.T.);
}

Scopus Author ID 7003552153

Received: 6.07.2021; Revised: 26.08.2021; Accepted: 2.09.2021; Published: 18.10.2021

\begin{abstract}
The p38-alpha (MAPK14) is a protein kinase that is implicated in the pathological mechanisms of BAG3 ${ }^{\mathrm{P} 209 \mathrm{~L}}$ myofibrillar myopathy, cancers, and inflammatory diseases like Alzheimer's and rheumatoid arthritis. Inhibition of p38 has shown promise as a treatment for these diseases. Traditional drug discovery methods could not create effective and safe small molecule inhibitors, so we used machine learning to elucidate potential p38 blockers from existing FDA-approved drugs. Using PubChem bioactivity data, we determined the best existing p38 inhibitors and applied fingerprint clustering to isolate the compounds with similar structures. Descriptors were calculated for these clustered compounds, and the most important of these descriptors were determined through a machine learning-based feature selection algorithm. This data served as the training set for a deep neural network that was fine-tuned to a $92 \%$ validation accuracy. The neural network model was applied to a database of FDA-approved drugs, revealing 149 potential p38 inhibitors, whose efficacy was confirmed by docking simulations to be statistically significantly higher than random FDA drugs and slightly higher than known inhibitors. Our study not only reveals potential medications for p38-mediated diseases that we recommend for physical trials but also demonstrates the ability of our novel deep learning-based computational pipeline to predict new functions of existing pharmaceuticals.
\end{abstract}

Keywords: p38; MAPK; computational drug design; myopathy; cancer; deep learning.

(C) 2021 by the authors. This article is an open-access article distributed under the terms and conditions of the Creative Commons Attribution (CC BY) license (https://creativecommons.org/licenses/by/4.0/).

\section{Introduction}

P38-alpha, or MAPK14, is a mitogen-associated protein kinase that is activated by dual phosphorylation of a tripeptide motif (Thr-Xaa-Tyr) located in its activation loop. The p38 kinase is regulated by stress-activated MAPK Kinase 3 (MKK3), MKK6, and MKK4. Its signaling cascade is ultimately responsible for releasing proinflammatory cytokines such as TNF, IL1, and IL6 [1-3]. P38 has been found to play a large role in the inflammatory mechanisms of rheumatoid arthritis, Alzheimer's disease, Parkinson's disease, Crohn's disease, and several types of myopathies and lung diseases. It has also shown tumor promotion properties in different types of cancer, including breast, liver, and colorectal cancer [4,5]. P38's contribution to the severe 
phenotype of so many degenerative diseases has made it an attractive target for treatment via molecular inhibitors.

Myofibrillar myopathy (MFM) is another disease in which p38 plays a significant role. One cause of this disease is a mutation in the Bcl2-associated athanogene 3 (BAG3) protein. The modular domain composition of the BAG3 co-chaperone makes it incredibly versatile in its interactions with other molecules. It suppresses apoptosis, mediates selective autophagy, and maintains cellular homeostasis during stress, making it important in various diseases, including cancers, myopathies, and neurodegeneration [6]. A BAG3 missense mutation of P209 into leucine and several other mutations in the same site have been shown to result in a severe childhood MFM phenotype, characterized by progressive limb and axial muscle weakness, respiratory insufficiency, and cardiomyopathy. Three of 53 random MFM patients showed the P209 mutation [7,8]. Further investigation of the P209L mutation in zebrafish discovered that the mutation leads to a toxic aggregation of mutated BAG3, ultimately causing a deficiency of functional BAG3, triggering myofibrillar disintegration [9]. Research on $\mathrm{BAG} 3^{\mathrm{P} 209 \mathrm{~L}}$ mice found significantly increased activation of $\mathrm{p} 38$. The mechanism of $\mathrm{p} 38$ activation is similar to that seen in Alzheimer's and other tauopathies and neurodegenerative diseases, in which oxidative cell stress activates the MAPK signaling pathway, causing an inflammatory response $[8,10,11]$. In these brain diseases, cellular stress is caused by misfolded amyloid-beta and tau proteins, while in BAG3 ${ }^{\text {P209L }}$ MFM, cellular stress results from a lack of functional selective autophagy [10, 12]. Targeted activation of p38 in vivo has been shown to induce heart failure, and cardiac hypertrophy similar to that seen in the mutant mice, which also show increases in inflammatory infiltrates and activation of NF- $\kappa \mathrm{B}$, a prototypical proinflammatory signaling pathway which is characteristic of p38 activation $[8,11$ 13]. All this evidence points to targeted inhibition of $\mathrm{p} 38$ as an effective treatment of BAG3 mutation caused MFM. Our research is the first attempt to discover p38 inhibitors as a treatment for genetic myopathy.

Similar to other protein kinase inhibitors, MAPK14 inhibitors mostly function through competitive inhibition at the ATP-binding site. There are two types of these competitive inhibitors: Type 1, which binds in the active DGF-in conformation (e.g., compound SB 203580), and Type 2, which binds in the inactive DFG-out conformation (e.g., compound Birb 796) [14]. The two binding modes differ in the orientation of the DFG motif within the ATP pocket [15]. Many different p38 inhibitors have been, or are currently being, investigated in phase I or II clinical trials, including Birb 796 and VX-745, but none have been recommended for use, mostly due to high toxicity or lack of significant efficacy. Since existing p38 inhibitors have been artificially synthesized, their side effects are unknown until human clinical trials, which is why even though they may work very well during in-vitro trials or in in-vivo animal models, they fail at the clinical trials. The development of new drugs is a very long and expensive process. This project proposes repurposing existing FDA-approved drugs to find functional, non-toxic p38 inhibitors with already known side effects. FDA drug repurposing significantly expedites the drug discovery process, delivering safe yet effective treatments to patients in a much timelier manner.

There have been a few attempts to use computational techniques to find p38 kinase inhibitors, using structure-based virtual screening or structure-based design of novel inhibitors [1619]. However, there has been no use of deep learning (DL) to repurpose FDA-approved drugs as p38 inhibitors that we are aware of. Deep learning is a complex and powerful subset of machine 
learning that uses many nodes, hidden layers, and learning algorithms modeled after the neuronal structure of the human brain itself [20]. Although computationally intensive, it has shown immense promise in a variety of applications, from image recognition to video games to language translation to neuroscience $[21,22]$. But this artificial intelligence technology has also recently emerged as one of the most effective tools in all aspects of drug discovery, including bioactivity prediction, target prediction, identification of prognostic biomarkers, and even the removal of biases and impurities from available drug data [23,24,25]. Deep learning has shown significant advantages over other forms of machine learning and statistical models because of the depth and variety of its architecture, which allows it to deal with large amounts of data of different types [26]. Simultaneous advancements in data mining, curation, and management techniques have also contributed to the success of deep learning in pharmacology [27]. Furthermore, data-filtration techniques like fingerprint clustering and feature selection have been shown to significantly increase deep-learning accuracy by helping mitigate the "curse of dimensionality" associated with the vast amount of input data required for machine learning [28,29,30]. In this study, we utilized these data preparation algorithms along with a robust deep neural network to discover which FDAapproved drugs could also function as p38 inhibitors, revealing 149 candidates. These predictions were then ranked through ligand-docking, a structure-based virtual screening method that calculates how thermodynamically favorable the binding of a ligand to a protein is [31]. Despite imperfections, docking simulations have historically shown great promise as in silico drug discovery tools, especially with technology developments in recent years [32]. Their convenience and efficiency have also made virtual screening by docking simulations a popular, effective tool in the recent search for SARS-CoV-2 treatments [33,34]. With corroboration from experimental trials, the most promising of these drugs could be used as a treatment for BAG3 ${ }^{\mathrm{P} 209 \mathrm{~L}} \mathrm{MFM}$ or other diseases with similar p38-mediated pathological mechanisms.

\section{Materials and Methods}

All research was completed in silico. The programs, tools, and websites used were PubChem, DrugBank, CADD group Cheminformatics Tools and User Services (CACTUS), Molecular Operating Environment (MOE), Waikato Environment for Knowledge Analysis (Weka), PaDEL-Descriptor, TensorFlow, Netron, Net2Vis, and the Matplotlib, and Seaborn Python libraries. [35-45].

\subsection{Clustering.}

Activity values and structure files for 12,456 compounds tested with the p38 kinase were retrieved from PubChem [35]. To limit the tested compounds to the strongest inhibitors, only those with an activity value ( $\mathrm{IC}_{50}, \mathrm{Kd}, \mathrm{Ki}$ ) less than $100 \mathrm{nM}$ were considered. These compounds were then analyzed with the $\mathrm{MOE}^{27}$ fingerprint clustering function, which uses Jarvis-Patrick Clustering to determine compounds with similar structures and pharmacophores to improve the specificity of the deep-learning model. Clustering parameters were set at $56 \%$ similarity and overlap, revealing 297 clusters. The largest of these clusters contained 1,206 compounds and was what the deep-learning model would be trained on. The final predicted inhibitors also underwent fingerprint clustering with the same parameters to provide more information about the results. 
Since clustering is based on the molecule's 3D structure, the structure files inputted to the software included 3D coordinates. So, we converted SMILES, which are a structural representation consisting of one-dimensional ASCII strings, into a 3D Spatial Data File (SDF) format using the CACTUS Structure Files Generator [37]. The SDF files were then imported to the MOE database.

\subsection{Descriptor calculation.}

PaDEL-Descriptor is a graphical or command-line interface that mostly utilizes the Chemistry Development Kit and a few additional descriptor categories [40]. It was employed to calculate 1,875 one-, two-, and three-dimensional descriptors. These descriptors - the data that the deep-learning model analyzes to train and make predictions-were calculated for threedimensional SDFs of the largest cluster of known inhibitors, for random molecules (control group) pulled from PubChem, and for FDA-approved drugs retrieved from DrugBank [36].

\subsection{Feature selection.}

To narrow down the calculated descriptors to only the most significant ones, we employed attribute selection from WEKA, an open-source machine learning software [39]. The descriptors were ranked by the Information Gain Attribute Evaluation (InfoGain) function, an unsupervised machine-learning algorithm that measures how important each descriptor is in determining whether a given molecule is an inhibitor or not. Only the most significant descriptors were selected to be used by the DL algorithm in order to reduce noise. Figure 1 is a histogram that illustrates the most informative descriptor, nAtomP. The vertical bars represent the number of molecules for each value of nAtomP, the length of the longest pi chain in the molecule. Inhibitors (red) tend to have larger values for nAtomP than non-inhibitors (blue). This clear distinction between the two is what makes this descriptor useful for deep-learning classification.

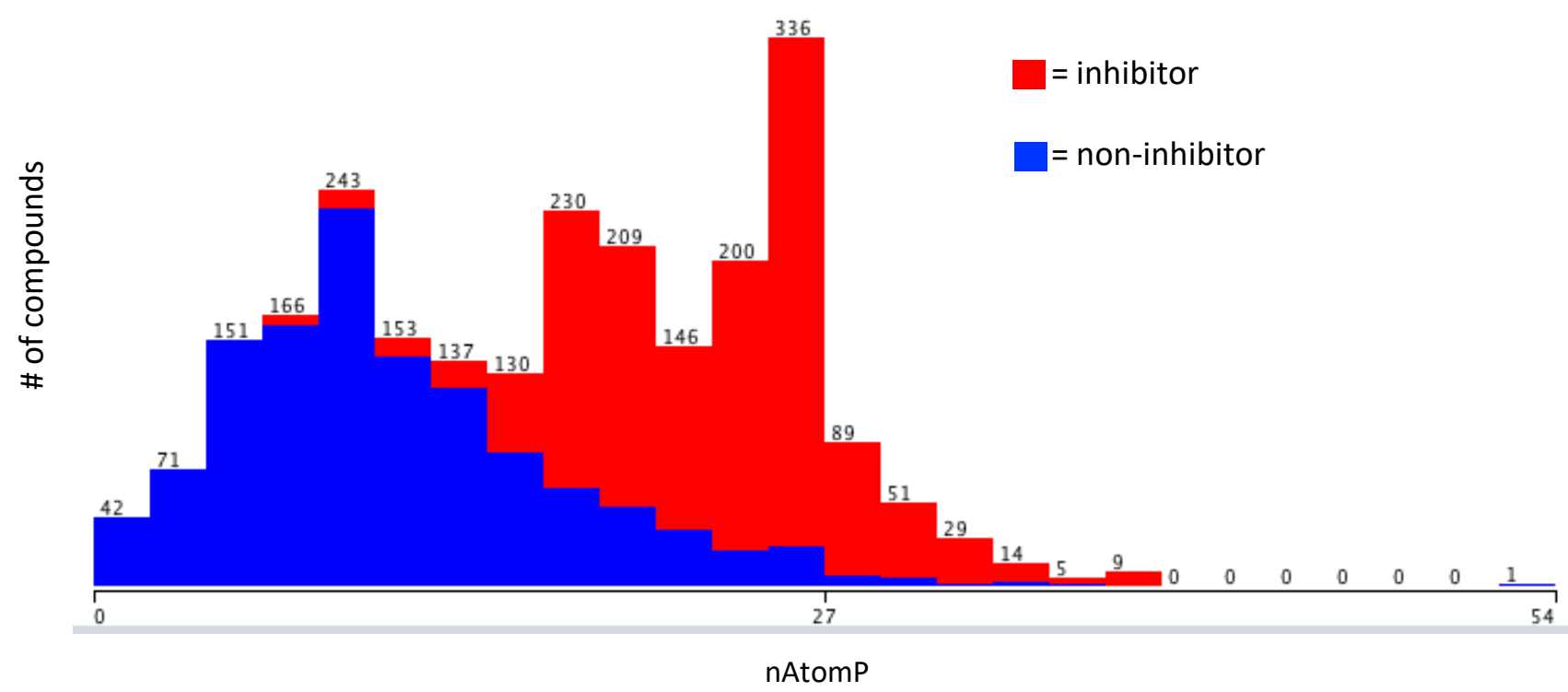

Figure 1. Histogram of the length of the largest pi chain in the molecule for all molecules in the training set. This descriptor, nAtomP, was ranked as most informative by an information gain algorithm. 


\subsection{Neural network construction.}

The deep-learning algorithm was created in Python and first converted the training data of known inhibitors' and random molecules' most important descriptors into a shuffled TensorFlow [41] dataset with an 80-20 train-validation split. The inhibitor label is removed and compared to the neural network's predictions to determine training and validation accuracy. The neural network (Figure 3) used was a Keras sequential model, a multilayer perceptron type. To determine the best parameters that maximized accuracy, we applied hyperparameter tuning with TensorBoard (TensorFlow's visualization kit), which looped over the training algorithm, adjusting each parameter one at a time (Figure 1). The hyperparameter tuning results indicated that the optimal algorithm trains with 7 hidden layers with 336 nodes each, 160 epochs (how many times the dataset passes through the model), 1 batch per epoch (maximum batch size), and a learning rate of 0.001 with the Adam optimizer.

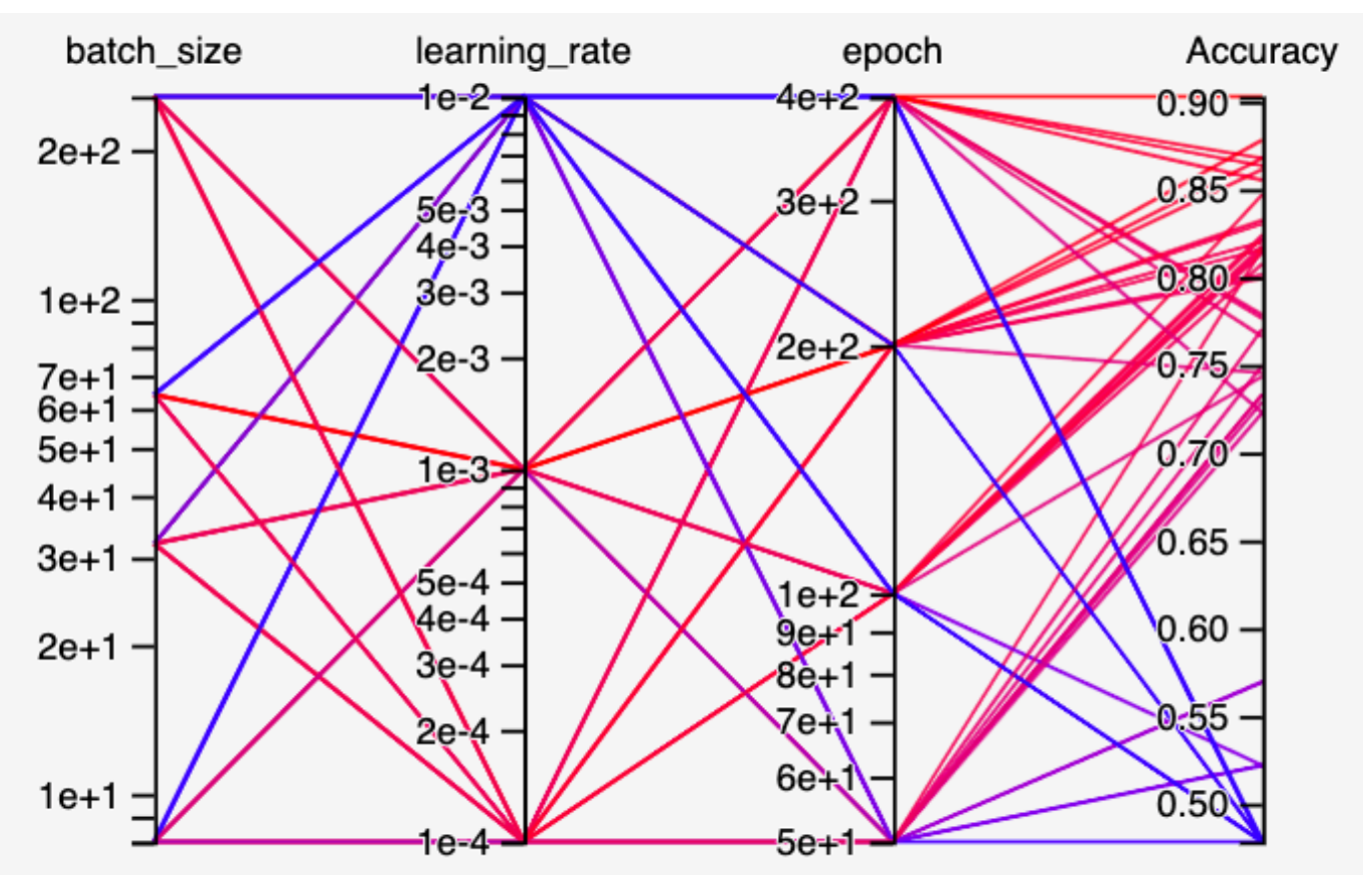

Figure 2. A visual representation of the hyperparameter tuning process. The parameters being considered here are batch size, learning rate, and number of epochs. The red lines represent effective combinations of parameters, while the blue lines are ineffective.

\subsection{Conformational search and docking.}

Preparation of a set of conformers was performed for each of the molecules. MOE's Conformations/Import function uses a stochastic search and energy minimization algorithm that finds all possible conformations of a molecule given limits on strain energy. We set the strain energy limit to $1 \mathrm{kcal} / \mathrm{mol}$ and restricted it to a maximum of 100 conformations per molecule.

The conformers were docked in MOE, using the Dock module, with the PDB structure 1A9U, a MAPK14 protein bound to the compound SB 203580, a strong known inhibitor, at the ATP-binding site. The protein structure was prepared by removing the inhibiting ligand, 3D protonation (determines the lowest energy configurations of titratable groups in the protein), and 
MOE's Structure Preparation module, which corrects any errors in the crystal structure. The conformers prepared through MOE's Conformations/Import module were then docked with the protein structure, determining five poses for each compound with the Triangle Matcher placement method and London $\mathrm{dG}$ scoring method. Then, the poses were refined with the Induced Fit mode (flexible docking) and scored for a final time with the GBVI/WSA dG method. The competitive binding site was determined through MOE's pocket function.

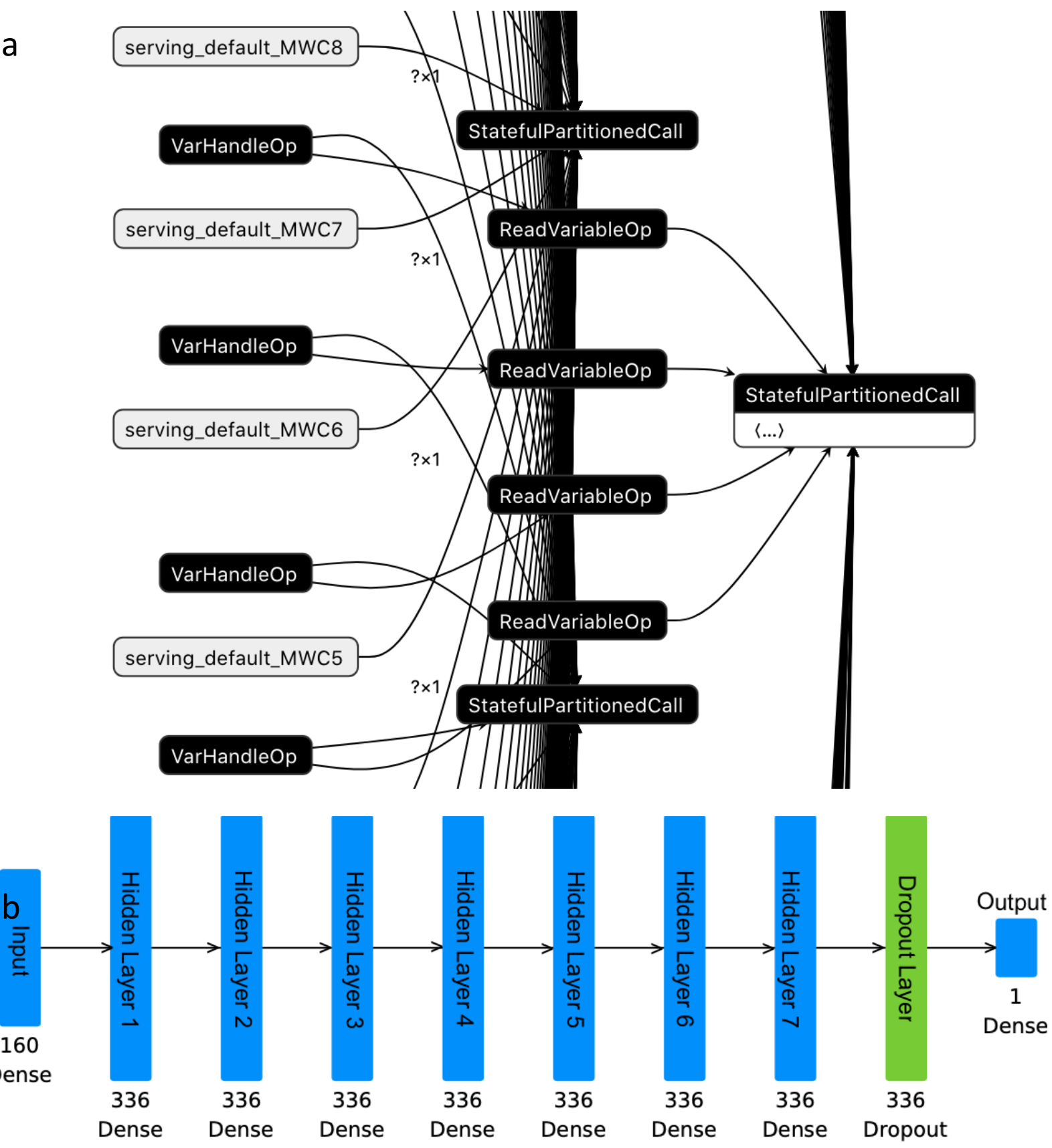

Figure 3. Neural network visualizations. (a) A snippet of a complex representation of the deep neural network showing how the input data of molecular descriptors connects to the different nodes of the first two hidden layers [42]. (b) This more simplified representation shows how the input data with the 160 descriptors travels through 7 different hidden layers with 336 nodes, a dropout layer (reduces overfitting to the training data by randomly setting input units to 0 ), and then a final output layer [43]. 


\section{Results and Discussion}

To present a comprehensive picture of all important compounds for repurposing, we engaged two scaling measures: first, by the docking scores of compounds to p38 (Table 2), and second, by the likelihood that the compounds inhibit p38 according to the deep-learning model (Table 5). We also combined the two scaling techniques in Table 6 to provide a more comprehensive ranking system. However, the first method's docking score is most reliable because it ranks the compounds directly by their simulated interactions with $\mathrm{p} 38$, which is most important in determining effective inhibitors.

\subsection{Docking.}

Our conformational search resulted in 8890 conformers of p38 inhibitors predicted by our neural network and 6616 conformers of already known p38 inhibitors, along with 5473 confirmations of random FDA drugs added as negative fits. These conformers were then docked with p38 and given a final GBVI/WSA score. The random control compounds had an average docking score of $-5.92 \mathrm{kcal} / \mathrm{mol}$, the known inhibitors had a score of -7.30 , and the predicted inhibitors had a score of -7.45 (Figure 4). A t-Test (Table 1) confirmed that the predicted inhibitors were statistically significantly better at binding to p38 at the ATP-binding site-therefore inhibiting p38's function - than random FDA-approved drugs (Since the docking results measure binding energy, a more negative value means stronger binding). The t-Test also shows that the performance of the predicted inhibitors is much more consistent, with a variance less than half that of the random control group. The compounds exhibiting the best docking energies are listed in Table 3 and displayed with the p38 binding pocket in Figure 5.

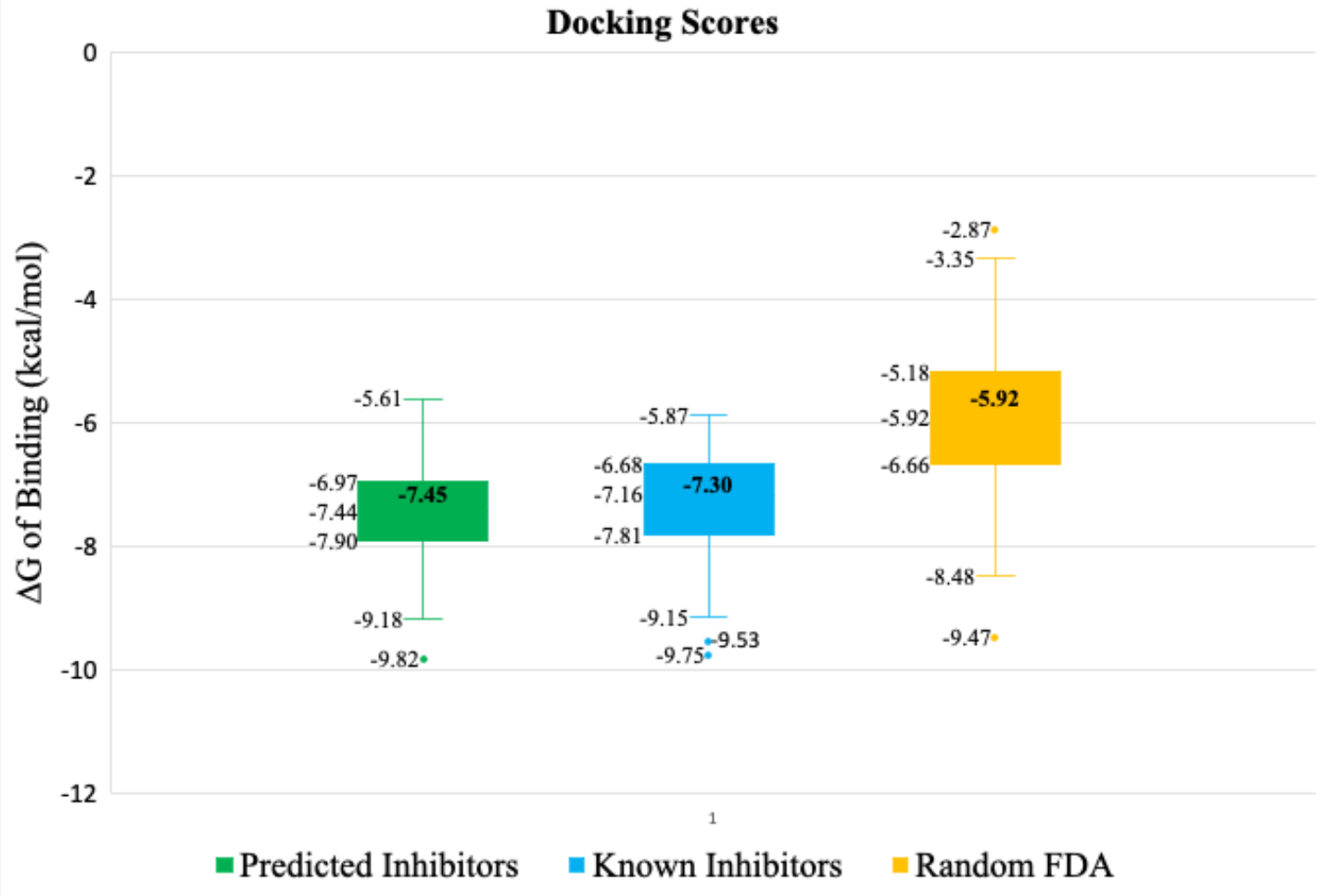

Figure 4. Docking scores (kcal/mol) for 149 predicted inhibitors, 149 selected known inhibitors, and 149 random FDA-approved drugs. 
Table 1. t-Test: Two-Sample Assuming Unequal Variances. Since t Stat $<-(t$ Critical two-tail), $-13.89<-1.97$, the difference between the predicted inhibitors' and random FDA-approved drugs' docking scores is statistically

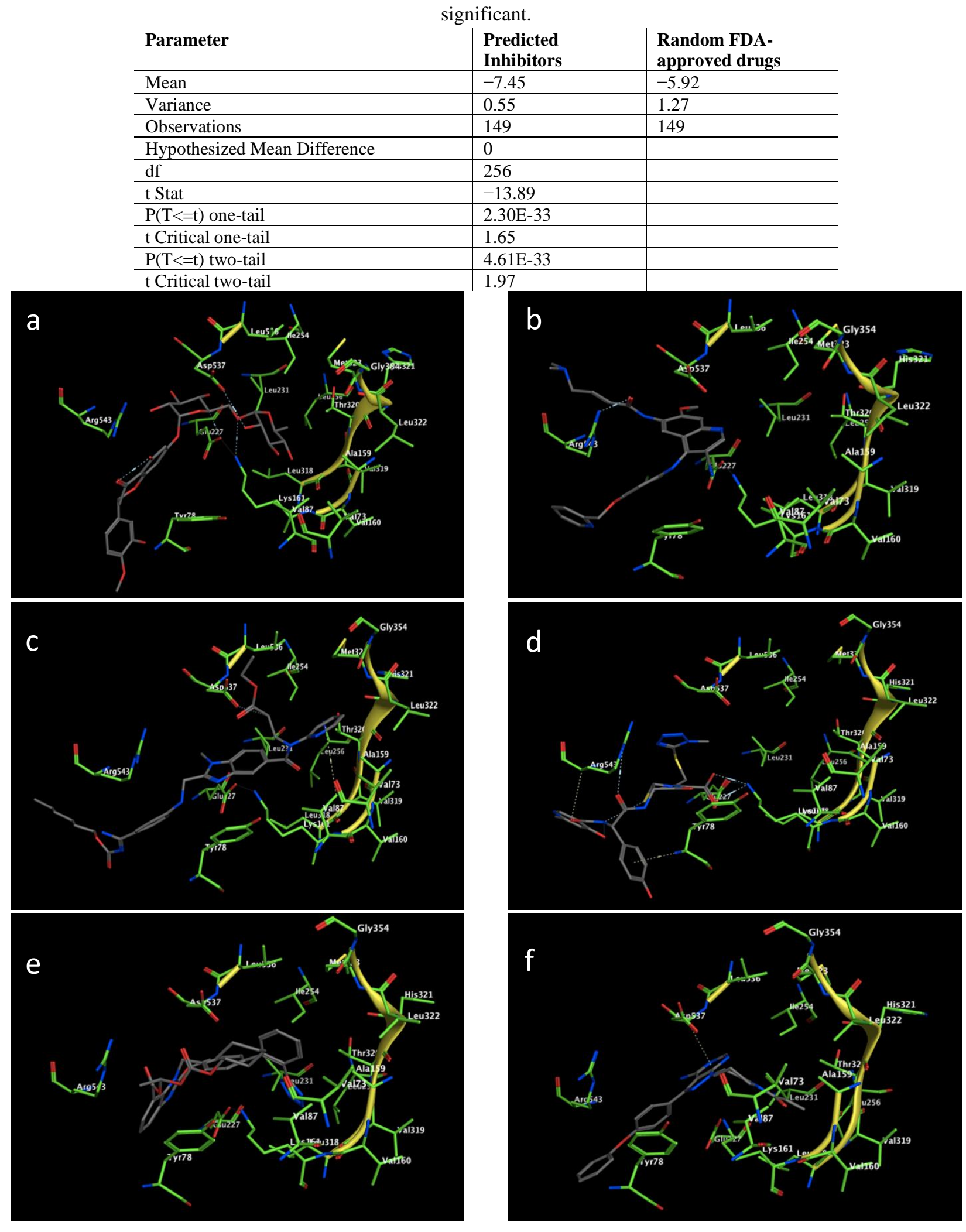



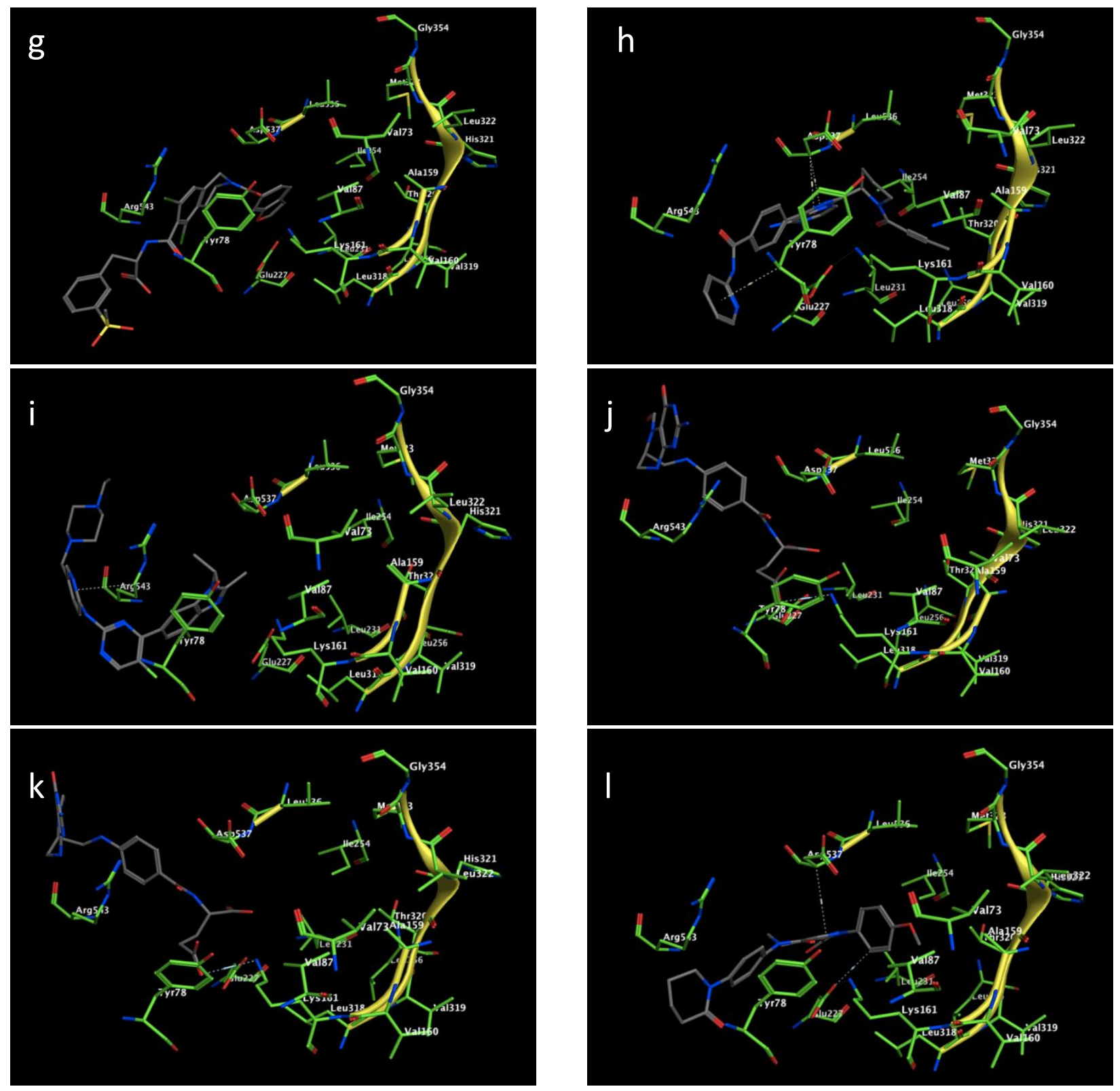

Figure 5. Docking of the top 12 predicted inhibitors by docking score with the p38 ATP-binding site: (a) hesperidin; (b) neratinib; (c) dabigatran etexilate; (d) cefpiramide; (e) candesartan cilexetil; (f) ibrutinib; (g) lifitegrast; (h) acalabrutinib; (i) abemaciclib; (j) leucovorin; (k) levoleucovorin; (l) apixaban.

Table 2 also includes the original uses and protein interactions of the top 40 predicted inhibitors according to docking score, as well as their clusters (see section 3.2). Of these 40, 34 already act as some kind of protein inhibitor, and 14 (35\%) act on protein kinases specifically, which share structural similarities with p38. By comparison, 52 of the 2151 FDA-approved drugs (only $2.4 \%$ ) used in this project are protein kinases. This means that the model and docking simulations successfully identify drugs that are already clinically proven to be inhibitors of proteins structurally similar to p38. 


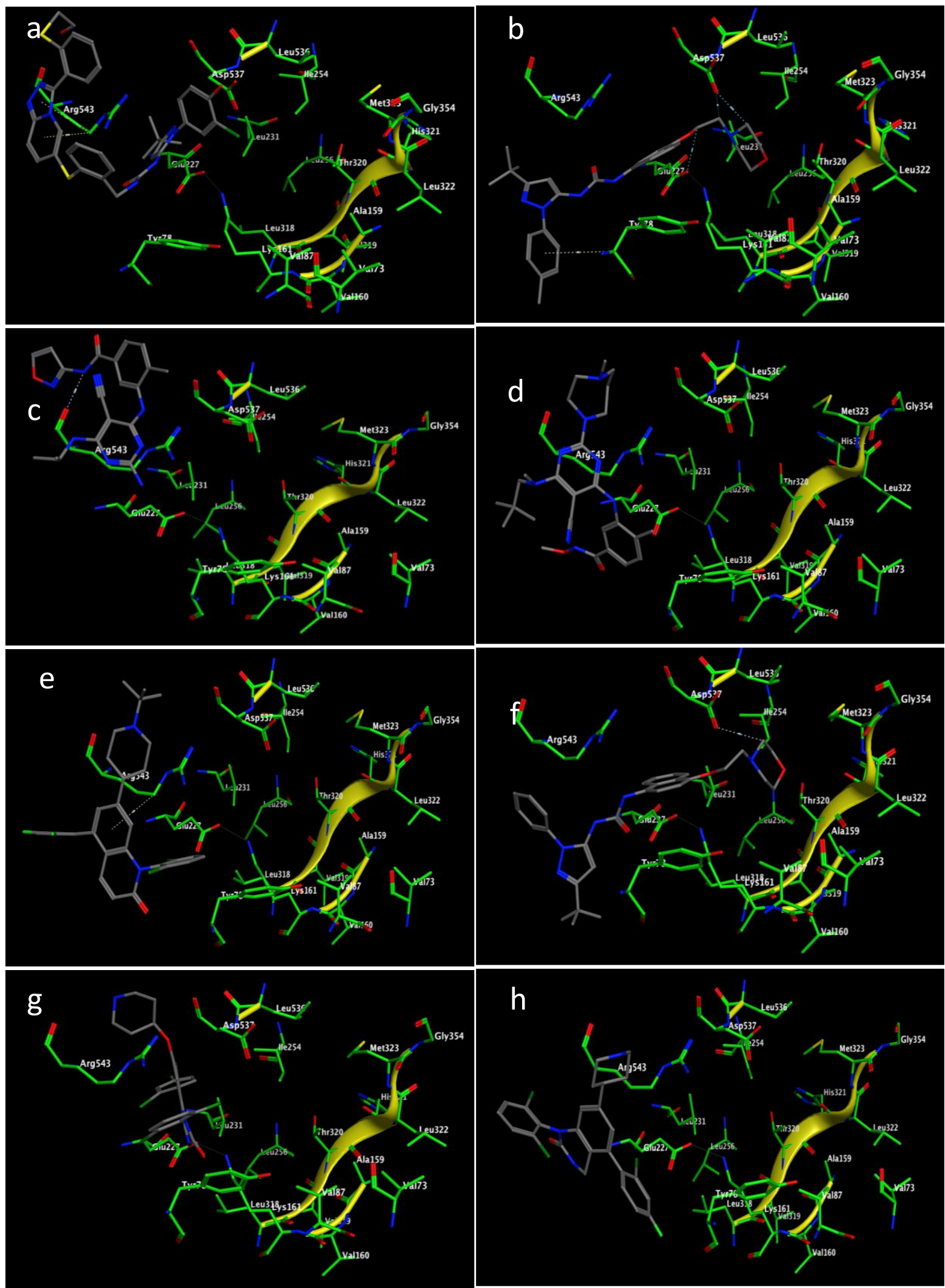

Figure 6. Docking of the top 8 selected known inhibitors (based on activity values) with the p38 ATP-binding site: (a) PF-03715455; (b) doramapimod (Birb 796); (c) CHEMBL197206; (d) CHEMBL196741; (e) CHEMBL199679; (f) CHEMBL318810; (g) CHEMBL327959; (h) CHEMBL328614. 
Table 2. Top 40 predicted inhibitors ranked by docking score.

\begin{tabular}{|c|c|c|c|c|}
\hline $\begin{array}{c}\text { Docking Score } \\
(\mathrm{kcal} / \mathrm{mol})\end{array}$ & Name & Cluster & Uses & Protein interactions \\
\hline-9.82 & Hesperidin & 1 & Treats blood vessel conditions & Inhibits lipase \\
\hline-9.18 & Neratinib & 25 & $\begin{array}{l}\text { Treats certain types of breast } \\
\text { cancer }\end{array}$ & $\begin{array}{l}\text { Inhibits human epidermal growth factor } \\
\text { receptor } 2 \text { (Her2) and epidermal growth } \\
\text { factor receptor (EGFR) tyrosine kinases }\end{array}$ \\
\hline-9.13 & $\begin{array}{l}\text { Dabigatran } \\
\text { etexilate }\end{array}$ & 4 & $\begin{array}{l}\text { Prevents stroke and harmful blood } \\
\text { clots }\end{array}$ & Inhibits thrombin \\
\hline-9.12 & Cefpiramide & 22 & Antibacterial agent & Inhibits penicillin-binding proteins (PBPs) \\
\hline-8.98 & $\begin{array}{l}\text { Candesartan } \\
\text { cilexetil }\end{array}$ & 53 & Treats hypertension & $\begin{array}{l}\text { Inhibits the type-1 angiotensin II receptor } \\
\text { (AT1) }\end{array}$ \\
\hline-8.97 & Ibrutinib & 4 & Treats certain cancers & $\begin{array}{l}\text { Inhibits Bruton's tyrosine kinase (BTK) } \\
\text { and other non-specific tyrosine kinases }\end{array}$ \\
\hline-8.96 & Lifitegrast & 31 & Treats dry eye disease & $\begin{array}{l}\text { Inhibits the interaction between } \\
\text { lymphocyte function-associated antigen } 1 \\
\text { (LFA-1) and intercellular adhesion } \\
\text { molecule } 1 \text { (ICAM-1) }\end{array}$ \\
\hline-8.89 & Acalabrutinib & 4 & Treats mantle cell lymphoma & Inhibits Bruton’s tyrosine kinase (BTK) \\
\hline-8.66 & Abemaciclib & 4 & $\begin{array}{l}\text { Treats certain types of breast } \\
\text { cancer }\end{array}$ & $\begin{array}{l}\text { Inhibits cyclin-dependent kinase (CDK) } 4 \\
\text { and } 6\end{array}$ \\
\hline-8.63 & Leucovorin & 133 & $\begin{array}{l}\text { Prevents harmful effects of } \\
\text { methotrexate }\end{array}$ & N/A \\
\hline-8.63 & Levoleucovorin & 133 & $\begin{array}{l}\text { Treats or prevents toxic effects of } \\
\text { methotrexate }\end{array}$ & N/A \\
\hline-8.62 & Apixaban & 4 & Prevents strokes or blood clots & Inhibits coagulation factor $\mathrm{Xa}$ \\
\hline-8.50 & Zafirlukast & 11 & Prevents asthma symptoms & $\begin{array}{l}\text { Inhibits cysteinyl leukotriene } 1 \text { receptor } \\
\text { (CYSLTR } 1 \text { ) }\end{array}$ \\
\hline-8.43 & Imatinib & 4 & Treats certain types of leukemia & $\begin{array}{l}\text { Inhibits the BCR-ABL, platelet-derived } \\
\text { growth factor (PDGF), and stem cell factor } \\
\text { (SCF)/c-kit tyrosine kinases }\end{array}$ \\
\hline-8.42 & Edoxaban & 4 & Prevents strokes or blood clots & Inhibits coagulation factor $\mathrm{Xa}$ \\
\hline-8.37 & Lusutrombopag & 95 & Treats thrombocytopenia & $\begin{array}{l}\text { Activates the thrombopoietin (TPO) } \\
\text { receptor }\end{array}$ \\
\hline-8.34 & Argatroban & 83 & Treats or prevents blood clots & Inhibits fibrin-bound thrombin \\
\hline-8.31 & Lapatinib & 58 & $\begin{array}{l}\text { Treats certain types of breast } \\
\text { cancer }\end{array}$ & $\begin{array}{l}\text { Inhibits human epidermal growth factor } \\
\text { receptor } 2 \text { (Her2) and epidermal growth } \\
\text { factor receptor (EGFR) tyrosine kinases }\end{array}$ \\
\hline-8.30 & Piperacillin & 22 & Antibiotic & Inhibits penicillin-binding proteins (PBPs) \\
\hline-8.25 & $\begin{array}{l}\text { Chloramphenicol } \\
\text { palmitate }\end{array}$ & 109 & Antibiotic & Inhibits bacterial peptidyl transferase \\
\hline-8.22 & Ximelagatran & 97 & Treats and prevents blood clots & Inhibits thrombin \\
\hline-8.20 & Ubrogepant & 4 & Treats migraines & $\begin{array}{l}\text { Inhibits the calcitonin gene-related peptide } \\
\text { (CGRP) receptor }\end{array}$ \\
\hline-8.07 & Bosutinib & 4 & Treats certain types of blood cancer & $\begin{array}{l}\text { Inhibits the BCR-ABL and Src tyrosine } \\
\text { kinases }\end{array}$ \\
\hline-8.06 & Telotristat ethyl & 122 & Treats carcinoid syndrome diarrhea & Inhibits tryptophan hydroxylase \\
\hline-8.06 & Fedratinib & 31 & Treats myelofibrosis & $\begin{array}{l}\text { Inhibits Janus-associated kinase } 2 \text { (JAK2) } \\
\text { and FMS-like tyrosine kinase } 3\end{array}$ \\
\hline-8.06 & Ponatinib & 4 & Treats a certain type of leukemia & $\begin{array}{l}\text { Inhibits several tyrosine kinases including } \\
\text { the BCR-ABL tyrosine kinase }\end{array}$ \\
\hline-8.05 & Doxazosin & 4 & $\begin{array}{l}\text { Treats hypertension and enlarged } \\
\text { prostate }\end{array}$ & Inhibits alpha- 1 adrenergic receptors \\
\hline-8.02 & Carindacillin & 8 & Antibiotic & Inhibits penicillin-binding proteins (PBPs) \\
\hline-7.99 & Netarsudil & 89 & Treats glaucoma & $\begin{array}{l}\text { Inhibits the Rho kinase (ROCK) and } \\
\text { norepinephrine transport }\end{array}$ \\
\hline-7.99 & Azlocillin & 22 & Antibiotic & Inhibits penicillin-binding proteins (PBPs) \\
\hline
\end{tabular}


https://doi.org/10.33263/BRIAC124.53845404

\begin{tabular}{|c|c|c|c|c|}
\hline $\begin{array}{l}\text { Docking Score } \\
\text { (kcal/mol) }\end{array}$ & Name & Cluster & Uses & Protein interactions \\
\hline-7.98 & Levomefolic acid & 133 & $\begin{array}{l}\text { Active metabolite of folic acid } \\
\text { used as a dietary supplement }\end{array}$ & N/A \\
\hline-7.98 & Entrectinib & 4 & $\begin{array}{l}\text { Treats a certain type of non-small } \\
\text { cell lung cancer }\end{array}$ & $\begin{array}{l}\text { Inhibits tropomyosin receptor kinases } \\
\text { (Trk) A, B and C, C-ros oncogene } 1 \\
\text { (ROS1) and anaplastic lymphoma kinase } \\
\text { (ALK) }\end{array}$ \\
\hline-7.98 & Cabozantinib & 2 & $\begin{array}{l}\text { Treats advanced renal cell } \\
\text { carcinoma }\end{array}$ & $\begin{array}{l}\text { Inhibits several different } \\
\text { receptor tyrosine kinases (RTKs), such as } \\
\text { hepatocyte growth factor receptors } \\
\text { (METs) and vascular endothelial growth } \\
\text { factor receptors (VEGFRs) }\end{array}$ \\
\hline-7.91 & Encorafenib & 31 & Treats certain types of cancer & Inhibits the serine/threonine Raf kinase \\
\hline-7.91 & Doxorubicin & 1 & Treats certain types of cancer & Inhibits topoisomerase II \\
\hline-7.90 & Arzoxifene & 19 & $\begin{array}{l}\text { Maintains bone density to prevent } \\
\text { fractures }\end{array}$ & $\begin{array}{l}\text { Selectively inhibits and activates estrogen } \\
\text { receptors as a selected estrogen receptor } \\
\text { modulator (SERM) }\end{array}$ \\
\hline-7.90 & Riociguat & 4 & $\begin{array}{l}\text { Treats pulmonary arterial } \\
\text { hypertension }\end{array}$ & Stimulates guanylate cyclase activity \\
\hline-7.90 & Erlotinib & 30 & $\begin{array}{l}\text { Treats certain types of non-small } \\
\text { cell lung cancer }\end{array}$ & $\begin{array}{l}\text { Inhibits the epidermal growth factor } \\
\text { receptor (EGFR) tyrosine kinase }\end{array}$ \\
\hline-7.90 & Ticagrelor & 81 & Prevents heart attack or stroke & $\begin{array}{l}\text { Blocks P2Y12 adenosine diphosphate } \\
\text { (ADP) receptors }\end{array}$ \\
\hline-7.89 & Eltrombopag & 10 & Increases platelet count & $\begin{array}{l}\text { Activates the platelet thrombopoietin } \\
\text { receptor (TPO-R) }\end{array}$ \\
\hline
\end{tabular}

Table 3 shows the 10 residues that interacted most frequently with the predicted compounds. Lys161 appears to be the most reactive residue, interacting through hydrogen bonds with about $80 \%$ of the ligands.

Table 3. Residues most frequently contact with inhibitors.

\begin{tabular}{l|c|c|c|l} 
Residue & $\begin{array}{l}\text { Frequency of } \\
\text { Interactions } \\
(\boldsymbol{\%})\end{array}$ & $\begin{array}{l}\text { Average } \\
\text { Distance }\end{array}$ & $\begin{array}{l}\text { Most Frequently } \\
\text { Interacting Residue } \\
\text { Atom }\end{array}$ & $\begin{array}{l}\text { Most Frequent Type } \\
\text { of Interaction }\end{array}$ \\
\hline Lys161 & 80 & 3.02 & NZ & H-Bond \\
\hline Arg543 & 70 & 3.23 & CD & Hydrophobic \\
\hline Glu227 & 50 & 3.30 & OE2 & H-Bond \\
\hline Leu231 & 50 & 3.71 & CD1 & Hydrophobic \\
\hline Tyr78 & 50 & 3.54 & CA & Hydrophobic \\
\hline Asp537 & 40 & 3.21 & OD1 & H-Bond \\
\hline Ala159 & 30 & 3.75 & CB & Hydrophobic \\
\hline Leu318 & 30 & 3.84 & CB & Hydrophobic \\
\hline Thr320 & 30 & 3.57 & CB & Hydrophobic \\
\hline Val87 & 30 & 4.03 & CG2
\end{tabular}

\subsection{Deep learning model.}

After the deep-learning algorithm was made and fine-tuned, it was run 5 times on a dataset of 2,151 FDA-approved molecules with the same 160 descriptors as the training set. Figure 7 shows a graph of the training metrics of the model while training for each of the 5 trials. The fact that the accuracy and AUC start at 0.5 , or random chance, but increase consistently with the epoch number, shows that the model is effective learning and improving over time. The 5 trials applied had an average validation accuracy of $91.6 \%$ and an area under the receiver-operator characteristic (ROC) curve (AUC) of 0.969 (Table 3). 
Table 4 contains both validation accuracy and AUC for each trial. Accuracy measures the number of correct predictions as a percentage of the total predictions. AUC is a slightly different but nonetheless important metric that demonstrates the model's ability to discriminate between two cases, which in this study are being an inhibitor or being a non-inhibitor. Our model's average AUC of 0.969 can be interpreted as meaning that $96.9 \%$ of the time, the model will correctly output a higher probability of inhibition for a randomly selected inhibitor than a randomly selected noninhibitory, even if the overall classification is incorrect.

Table 4. Metrics of deep-learning model predictions on validation set for all 5 trials .

\begin{tabular}{l|l|l} 
Trial & Validation Accuracy & \multicolumn{1}{|c}{ Validation AUC } \\
\hline 1 & 0.913043499 & 0.971671164 \\
\hline 2 & 0.910973072 & 0.964130163 \\
\hline 3 & 0.919254661 & 0.973077834 \\
\hline 4 & 0.917184293 & 0.96619153 \\
\hline 5 & 0.917184293 & 0.970728457 \\
\hline Average & $\mathbf{0 . 9 1 5 5 2 7 9 6 4}$ & $\mathbf{0 . 9 6 9 1 5 9 8 3 0}$
\end{tabular}
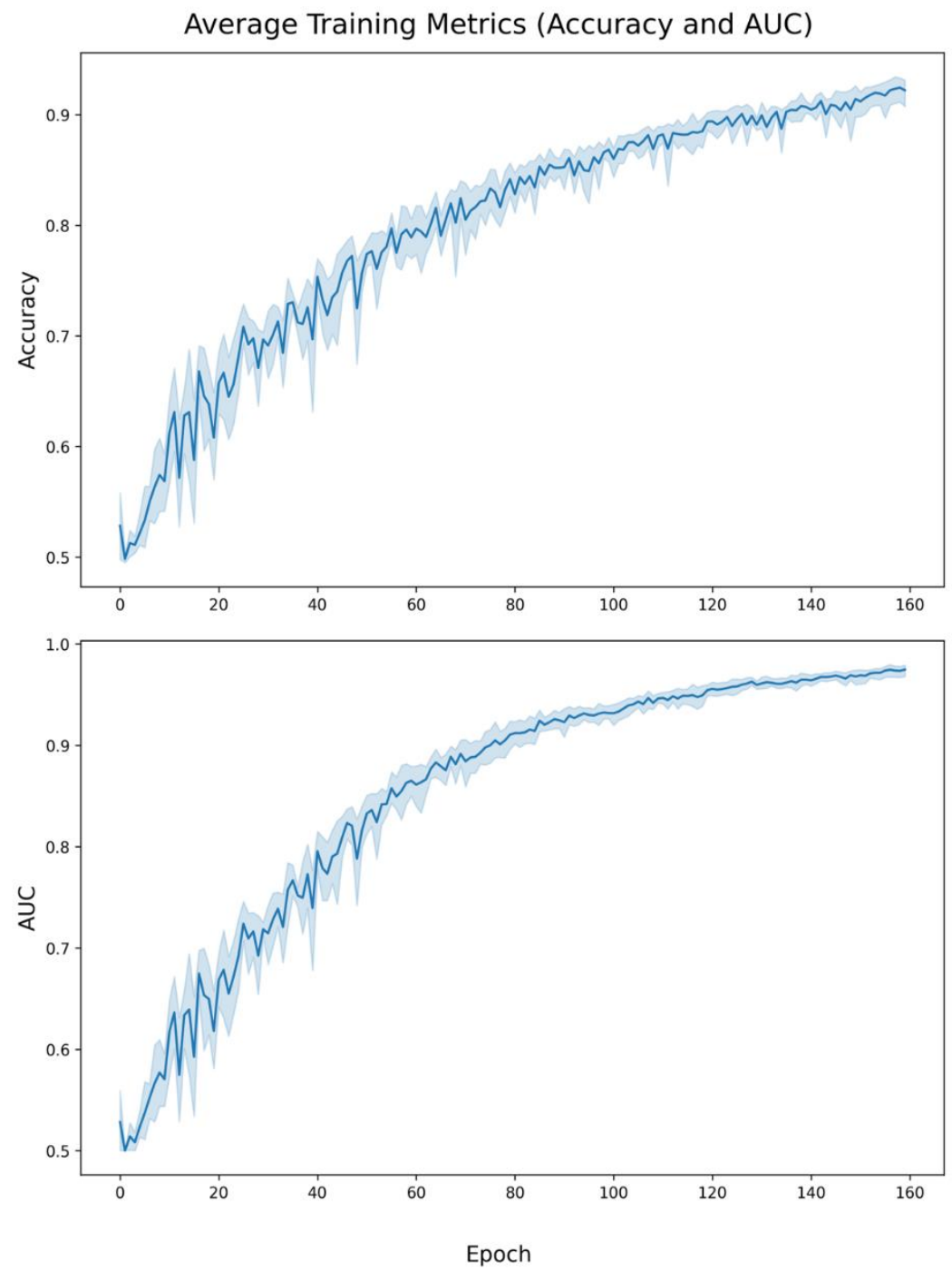

Figure 7. Training Accuracy and AUC over Time (epoch) averaged for all 5 trials of the DL model. The shaded region represents \pm 1 standard deviation. 
It's important to note that Figure 7 and Table 4 do not show the same metrics since Figure 7 shows the metrics while training, while Table 4 shows the metrics after training when the model is applied to the validation data, a data set randomly set aside from the training data. The validation metrics are a more accurate method of assessing a deep-learning model because they better simulate the model's performance on a separate dataset and confirm that a model is not just overfitting to the training data. So, our model can be expected to perform on FDA-approved drugs with the same accuracy that it does on the validation data. After synthesizing the results from all 5 trials, the deep-learning model classified 149 FDA-approved molecules as p38 inhibitors, with 27 of them having a greater than $90 \%$ chance.

Table 5 shows the top drug candidates ranked by the deep neural network score. For each given compound, the algorithm outputs a number between 0 and 1 . The closer the value is to 0 , the more likely it is a non-inhibitor, and the closer the value is to 1 , the more likely it is a p38 inhibitor. Thus, the output value can be interpreted as a probability of inhibition according to the deep-learning model. The compound with the highest probability of inhibition (0.99) is doxorubicin, which also has a strong docking score of -7.91 , making it a promising candidate. Table 6 lists the top 100 drug candidates ranked by combining their docking score rank and deeplearning-predicted rank. Although ranking by docking scores (Table 2) is the most reliable, combining these two ranking methods can present a more comprehensive picture of the best candidates. For example, ibrutinib, acalabrutinib, and hesperidin are the top two candidates by this joint scaling measure, with combined ranks of 10, 13, and 15, respectively. The fact that these compounds' incredibly high-performing docking scores are backed by the deep-learning model makes them some of the most promising candidates.

Table 5. Top 40 compounds ranked by deep-learning-predicted probability of inhibiting p38.

\begin{tabular}{|c|c|c|c|c|}
\hline DL rank & $\begin{array}{c}\text { Probability of } \\
\text { Inhibition }\end{array}$ & Name & Cluster & $\begin{array}{c}\text { Docking Score } \\
\text { kcal/mole }\end{array}$ \\
\hline 1 & 0.99 & Doxorubicin & 1 & -7.91 \\
\hline 2 & 0.98 & Cabozantinib & 2 & -7.98 \\
\hline 3 & 0.98 & Diacerein & 3 & -7.28 \\
\hline 4 & 0.98 & Ibrutinib & 4 & -8.97 \\
\hline 5 & 0.97 & Acalabrutinib & 4 & -8.89 \\
\hline 6 & 0.97 & Entrectinib & 4 & -7.98 \\
\hline 7 & 0.97 & Lenvatinib & 7 & -7.52 \\
\hline 8 & 0.96 & Carindacillin & 8 & -8.02 \\
\hline 9 & 0.96 & Deferasirox & 9 & -6.95 \\
\hline 10 & 0.96 & Eltrombopag & 10 & -7.89 \\
\hline 11 & 0.95 & Zafirlukast & 11 & -8.50 \\
\hline 12 & 0.94 & Ponatinib & 4 & -8.06 \\
\hline 13 & 0.94 & Daunorubicin & 1 & -6.65 \\
\hline 14 & 0.94 & Hesperidin & 1 & -9.82 \\
\hline 15 & 0.94 & Diosmin & 1 & -7.83 \\
\hline 16 & 0.94 & Imatinib & 4 & -8.43 \\
\hline 17 & 0.93 & Delafloxacin & 17 & -6.95 \\
\hline 18 & 0.93 & Selpercatinib & 18 & -7.69 \\
\hline 19 & 0.93 & Arzoxifene & 19 & -7.90 \\
\hline 20 & 0.92 & Idarubicin & 1 & -7.61 \\
\hline 21 & 0.92 & Trovafloxacin & 21 & -6.93 \\
\hline 22 & 0.92 & Piperacillin & 22 & -8.30 \\
\hline 23 & 0.91 & Perampanel & 23 & -6.56 \\
\hline
\end{tabular}




\begin{tabular}{r|c|l|r|c} 
DL rank & $\begin{array}{c}\text { Probability of } \\
\text { Inhibition }\end{array}$ & Name & Cluster & $\begin{array}{c}\text { Docking Score } \\
\text { kcal/mole }\end{array}$ \\
\hline 24 & 0.90 & Tucatinib & 24 & -7.67 \\
\hline 25 & 0.90 & Neratinib & 25 & -9.18 \\
\hline 26 & 0.90 & Avanafil & 4 & -7.61 \\
\hline 27 & 0.90 & Raloxifene & 19 & -7.21 \\
\hline 28 & 0.89 & Pralatrexate & 28 & -6.75 \\
\hline 29 & 0.88 & Dabigatran etexilate & 4 & -9.13 \\
\hline 30 & 0.88 & Erlotinib & 30 & -7.90 \\
\hline 31 & 0.88 & Bendroflumethiazide & 31 & -6.85 \\
\hline 32 & 0.88 & Dacomitinib & 33 & -7.00 \\
\hline 33 & 0.87 & Etravirine & 31 & -6.78 \\
\hline 34 & 0.87 & Amsacrine & 35 & -7.68 \\
\hline 35 & 0.86 & Nilotinib & 1 & -6.74 \\
\hline 36 & 0.86 & Cromoglicic Acid & 37 & -7.88 \\
\hline 37 & 0.86 & Azilsartan medoxomil & 35 & -7.19 \\
\hline 38 & 0.86 & Duvelisib & 31 & -8.06 \\
\hline 39 & 0.85 & Fedratinib & 40 & -5.61
\end{tabular}

Table 6. Top 100 predicted inhibitors, ordered by the sum of docking rank and deep-learning rank.

\begin{tabular}{|c|c|c|c|c|c|}
\hline $\begin{array}{l}\text { DL Rank + } \\
\text { Docking } \\
\text { Rank }\end{array}$ & Name & Cluster & $\begin{array}{l}\text { DL Rank + } \\
\text { Docking } \\
\text { Rank }\end{array}$ & Name & Cluster \\
\hline 10 & Ibrutinib & 4 & 129 & Chloramphenicol palmitate & 109 \\
\hline 13 & Acalabrutinib & 4 & 129 & Duvelisib & 35 \\
\hline 15 & Hesperidin & 1 & 130 & Ketoconazole & 4 \\
\hline 24 & Zafirlukast & 11 & 131 & Vemurafenib & 31 \\
\hline 27 & Neratinib & 25 & 131 & Delafloxacin & 17 \\
\hline 30 & Imatinib & 4 & 132 & Cefepime & 22 \\
\hline 32 & Dabigatran etexilate & 4 & 136 & Copanlisib & 4 \\
\hline 35 & Cabozantinib & 2 & 137 & Cefuroxime & 22 \\
\hline 36 & Carindacillin & 8 & 138 & Afatinib & 4 \\
\hline 36 & Doxorubicin & 1 & 138 & Pemetrexed & 28 \\
\hline 38 & Ponatinib & 4 & 138 & Trovafloxacin & 21 \\
\hline 38 & Entrectinib & 4 & 139 & Ubrogepant & 4 \\
\hline 41 & Piperacillin & 22 & 142 & Methotrexate & 70 \\
\hline 50 & Eltrombopag & 10 & 143 & Tadalafil & 42 \\
\hline 55 & Arzoxifene & 19 & 143 & Dacomitinib & 4 \\
\hline 58 & Candesartan cilexetil & 53 & 144 & Levoleucovorin & 133 \\
\hline 62 & Diosmin & 1 & 144 & Betrixaban & 79 \\
\hline 64 & Fedratinib & 31 & 144 & Daunorubicin & 1 \\
\hline 68 & Erlotinib & 30 & 146 & Telotristat ethyl & 122 \\
\hline 71 & Selpercatinib & 18 & 148 & Aclidinium & 102 \\
\hline 72 & Abemaciclib & 4 & 151 & Bendroflumethiazide & 31 \\
\hline 74 & Azlocillin & 22 & 152 & Amsacrine & 31 \\
\hline 76 & Lapatinib & 58 & 153 & Larotrectinib & 4 \\
\hline 76 & Lenvatinib & 7 & 154 & Ribociclib & 4 \\
\hline 80 & Azilsartan medoxomil & 37 & 154 & Lumacaftor & 71 \\
\hline 80 & Tucatinib & 24 & 155 & Nefazodone & 4 \\
\hline 81 & Idarubicin & 1 & 155 & Sulfinpyrazone & 67 \\
\hline 84 & Lifitegrast & 31 & 155 & Pralatrexate & 28 \\
\hline 86 & Riociguat & 4 & 156 & Olaparib & 56 \\
\hline 89 & Nilotinib & 35 & 157 & Leucovorin & 133 \\
\hline 89 & Avanafil & 4 & 157 & Etravirine & 33 \\
\hline
\end{tabular}




\begin{tabular}{l|l|c|l|l|c}
$\begin{array}{l}\text { DL Rank }+ \\
\text { Docking } \\
\text { Rank }\end{array}$ & & Cluster & $\begin{array}{l}\text { DL Rank } \\
\text { Docking } \\
\text { Rank }\end{array}$ & Name & Cluster \\
\hline 89 & Diacerein & 3 & 157 & Perampanel & 23 \\
\hline 90 & Edoxaban & 4 & 159 & Gefitinib & 4 \\
\hline 91 & Antrafenine & 4 & 160 & Cefoxitin & 22 \\
\hline 96 & Linagliptin & 4 & 161 & Apixaban & 4 \\
\hline 97 & Udenafil & 47 & 164 & Cromoglicic Acid & 1 \\
\hline 98 & Alatrofloxacin & 4 & 166 & Ripretinib & 62 \\
\hline 100 & Argatroban & 83 & 170 & Ceftazidime & 22 \\
\hline 103 & Erdafitinib & 45 & 173 & Lumefantrine & 98 \\
\hline 106 & Encorafenib & 31 & 173 & Apalutamide & 66 \\
\hline 107 & Cefpiramide & 22 & 173 & Isavuconazonium & 61 \\
\hline 108 & Montelukast & 57 & 174 & Suvorexant & 4 \\
\hline 111 & Lusutrombopag & 95 & 174 & Acemetacin & 96 \\
\hline 111 & Bosutinib & 4 & 175 & Topotecan & 50 \\
\hline 117 & Raloxifene & 19 & 176 & Dabrafenib & 31 \\
\hline 118 & Ximelagatran & 97 & 177 & Levomefolic acid & 133 \\
\hline 118 & Netarsudil & 89 & 179 & Macimorelin & 80 \\
\hline 120 & Ticagrelor & 81 & 181 & Cefditoren & 22 \\
\hline 124 & Deferasirox & 4 & 184 & Ezetimibe & 43 \\
\hline 128 & Doxazosin & 189 & Cefotaxime & 22 \\
\hline & & & & \\
\hline
\end{tabular}

\subsection{Clustering.}

Fingerprint clustering of the predicted inhibitors resulted in 78 clusters. The flexible alignments of the four largest clusters created by MOE's Database Viewer/Compute/Fingerprints/Clusters submodule are shown in Figure 8. The clusters are groups of predicted inhibitors with similar pharmacophore features and can be used to classify the compounds further and determine the best candidates. For example, certain clusters tend to outperform the average predicted inhibitor, making members of that group more promising drug candidates due to shared structural features with other strong candidates. One such cluster is number 4, which, as seen in Tables 2, 5, and 6, contains many of the top candidates like dabigatran etexilate, Ibrutinib, acalabrutinib, and abemaciclib. Furthermore, despite making up only $23.5 \%$ of all 149 predicted inhibitors, cluster 4 compounds make up 32.5\% of the top 40 compounds by docking score, making members of this cluster more promising candidates.

\section{Conclusions}

We elucidated and scored 149 potential p38 inhibitors, the highest-ranked of which we recommend for in vitro and in vivo validation. With an average validation accuracy of $92 \%$ and an area under the ROC curve of 0.97 , the deep learning model has shown significant efficacy in predicting the ability of a compound to inhibit $\mathrm{p} 38$. Furthermore, protein docking scores indicate that our predicted inhibitors are statistically significantly better (Table 1) than random FDAapproved molecules and even slightly better than the top known p38-inhibitors. Following experimental trials, these compounds could be used to treat various p38-mediated diseases, including MFM, cancers, and inflammatory diseases like rheumatoid arthritis and Alzheimer's.

One significant advantage of our project is its application to FDA-approved drugs. The repurposing of FDA-approved drugs has many practical benefits, especially for p38 inhibitors. 
Many of the most common and potent p38 inhibitors do well in vitro experiments, but fall short during in vivo or human trials due to unexpected side effects or issues with toxicity [1]. When repurposing approved drugs, however, the compound's safety has been studied extensively by the FDA and often other organizations like the European Medicines Agency (EMA) [46]. This not only ensures that a drug is safe and its side effects are well documented, but it also significantly cheapens and shortens the researcher to the patient pipeline, which normally takes an average of 10-15 years because doctors can provide off-label prescriptions before official approval [47].

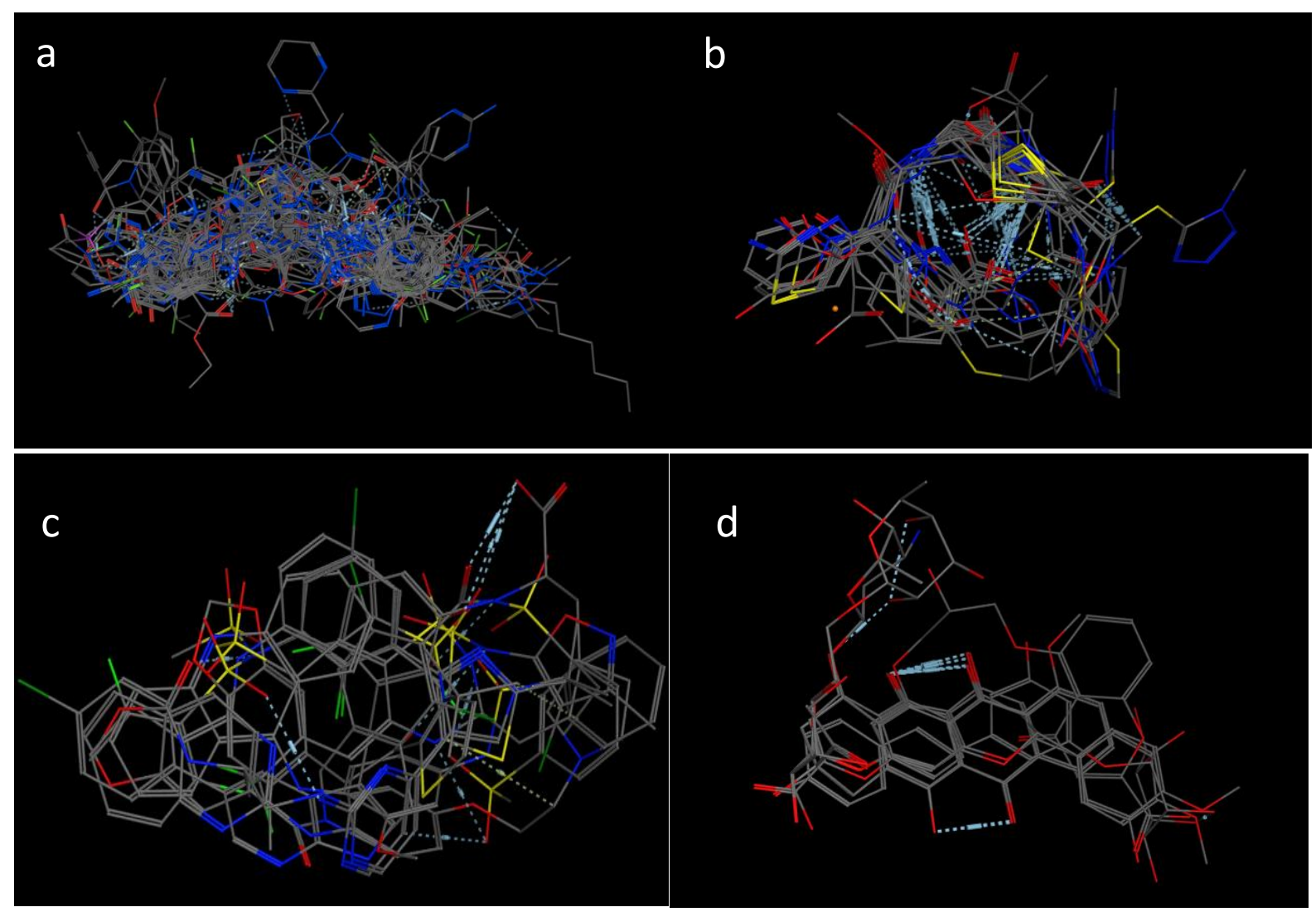

Figure 8. The four largest clusters of predicted compounds: (a) Cluster 4, 35 molecules; (b) Cluster 11, 13 molecules; (c) Cluster 98, 8 molecules; (d) Cluster 1, 7 molecules.

The response to the COVID-19 pandemic has shown first-hand how efficient drug repurposing can be in making treatments rapidly available [48]. This process has also shown promise in efficiently developing cancer treatments that are cheap yet effective [49]. Thus, if clinical trials bode well, our repurposed inhibitors could very soon be available to patients suffering from potentially life-threatening p38-mediated diseases.

It is important to note that the computational procedure described in this study is highly versatile as it is not $\mathrm{p} 38$-specific, meaning it can be utilized to repurpose existing drugs as structural inhibitors or activators for any protein target. The procedure is not specific to FDA-approved drugs, meaning it can be applied to any dataset of drugs or compounds for which chemical descriptors can be calculated, albeit their side effects may be unknown, and the process may be more computationally intensive depending on the size of the dataset. Another advantage of this procedure is the preprocessing of training data through fingerprint clustering and feature selection, which allows the deep learning model to operate more effectively as it no longer has to sift through 
noisy, irrelevant data. Fingerprint clustering removes structural outliers that can interfere with the results, while feature selection improves efficiency by elucidating only the most informative descriptors.

Traditional drug research and development is a long and tedious process that has become incredibly inefficient relative to the amount of money put in. In fact, "the number of new drugs approved per billion US dollars spent on R\&D has halved roughly every 9 years since 1950" [50]. Although in silico research cannot replace empirical trials, it allows us to efficiently and cheaply elucidate promising drug candidates to expedite the creation of new treatments [51], especially when multiple computational procedures are used in tandem, as in our methodology. Furthermore, as new artificial intelligence technologies emerge and the amount of accessible biochemical data grows, computational frameworks like ours will continue to improve the drug discovery process and allow for unprecedented advancements in the pharmaceutical field.

\section{Funding}

IT and VK were partially funded by Alexander's Way Research Fund.

\section{Acknowledgments}

We thank CCG (Montreal) for their support.

\section{Conflicts of Interest}

The authors declare no conflict of interest.

\section{References}

1. Hammaker, D.; Firestein, G.S. "Go Upstream, Young Man": Lessons Learned from the P38 Saga. Annals of the Rheumatic Diseases 2010, 69, i77-i82, https://doi.org/10.1136/ard.2009.119479.

2. Brancho, D. Mechanism of P38 MAP Kinase Activation in Vivo. Genes \& Development 2003, 17, 1969-1978, https://doi.org/10.1101/gad.1107303.

3. Schett, G.; Zwerina, J.; Firestein, G. The P38 Mitogen-Activated Protein Kinase (MAPK) Pathway in Rheumatoid Arthritis. Annals of the Rheumatic Diseases 2008, 67, 909-916, https://doi.org/10.1136/ard.2007.074278.

4. Cuenda, A.; Rousseau, S. P38 MAP-Kinases Pathway Regulation, Function and Role in Human Diseases. Biochimica et Biophysica Acta (BBA) - Molecular Cell Research 2007, 1773, 1358-1375, https://doi.org/10.1016/j.bbamcr.2007.03.010.

5. Gaffey, K.; Reynolds, S.; Plumb, J.; Kaur, M.; Singh, D. Increased Phosphorylated P38 Mitogen-Activated Protein Kinase in COPD Lungs. Eur Respir J 2013, 42, 28-41, https://doi.org/10.1183/09031936.00170711.

6. Behl, C. Breaking BAG: The Co-Chaperone BAG3 in Health and Disease. Trends in Pharmacological Sciences 2016, 37, 672-688, https://doi.org/10.1016/j.tips.2016.04.007.

7. Selcen, D.; Muntoni, F.; Burton, B.K.; Pegoraro, E.; Sewry, C.; Bite, A.V.; Engel, A.G. Mutation in BAG3 Causes Severe Dominant Childhood Muscular Dystrophy. Ann Neurol. 2008, 65, 83-89, https://doi.org/10.1002/ana.21553.

8. Quintana, M.T.; Parry, T.L.; He, J.; Yates, C.C.; Sidorova, T.N.; Murray, K.T.; Bain, J.R.; Newgard, C.B.; Muehlbauer, M.J.; Eaton, S.C.; et al. Cardiomyocyte-Specific Human Bcl2-Associated Anthanogene 3 P209L Expression Induces Mitochondrial Fragmentation, Bcl2-Associated Anthanogene 3 Haploinsufficiency, and Activates P38 Signaling. The American Journal of Pathology 2016, 186, 1989-2007, https://doi.org/10.1016/j.ajpath.2016.03.017. 
9. Ruparelia, A.A.; Oorschot, V.; Vaz, R.; Ramm, G.; Bryson-Richardson, R.J. Zebrafish Models of BAG3 Myofibrillar Myopathy Suggest a Toxic Gain of Function Leading to BAG3 Insufficiency. Acta Neuropathol 2014, 128, 821-833, https://doi.org/10.1007/s00401-014-1344-5.

10. Giraldo, E.; Lloret, A.; Fuchsberger, T.; Viña, J. A $\beta$ and Tau Toxicities in Alzheimer's Are Linked via Oxidative Stress-Induced P38 Activation: Protective Role of Vitamin E. Redox Biology 2014, 2, 873-877, https://doi.org/10.1016/j.redox.2014.03.002.

11. Zilka, N.; Kazmerova, Z.; Jadhav, S.; Neradil, P.; Madari, A.; Obetkova, D.; Bugos, O.; Novak, M. Who Fans the Flames of Alzheimer's Disease Brains? Misfolded Tau on the Crossroad of Neurodegenerative and Inflammatory Pathways. J Neuroinflammation 2012, 9, 544, https://doi.org/10.1186/1742-2094-9-47.

12. Liao, P.; Georgakopoulos, D.; Kovacs, A.; Zheng, M.; Lerner, D.; Pu, H.; Saffitz, J.; Chien, K.; Xiao, R.-P.; Kass, D.A.; et al. The in Vivo Role of P38 MAP Kinases in Cardiac Remodeling and Restrictive Cardiomyopathy. Proceedings of the National Academy of Sciences 2001, 98, 12283-12288, https://doi.org/10.1073/pnas.211086598.

13. Wang, Y.; Huang, S.; Sah, V.P.; Ross, J.; Brown, J.H.; Han, J.; Chien, K.R. Cardiac Muscle Cell Hypertrophy and Apoptosis Induced by Distinct Members of the P38 Mitogen-Activated Protein Kinase Family. Journal of Biological Chemistry 1998, 273, 2161-2168, https://doi.org/10.1074/jbc.273.4.2161.

14. Swann, S.L.; Merta, P.J.; Kifle, L.; Groebe, D.; Sarris, K.; Hajduk, P.J.; Sun, C. Biochemical and Biophysical Characterization of Unique Switch Pocket Inhibitors of P38a. Bioorganic \& Medicinal Chemistry Letters 2010, 20, 5787-5792, https://doi.org/10.1016/j.bmcl.2010.04.097.

15. Next Generation Kinase Inhibitors: Moving beyond the ATP Binding/Catalytic Sites; Shapiro, P., Ed.; Springer: Cham, Switzerland 2020; ISBN 9783030482831.

16. Shah, N.G.; Tulapurkar, M.E.; Ramarathnam, A.; Brophy, A.; Martinez, R.; Hom, K.; Hodges, T.; Samadani, R.; Singh, I.S.; MacKerell, A.D.; et al. Novel Noncatalytic Substrate-Selective P38 $\alpha$-Specific MAPK Inhibitors with Endothelial-Stabilizing and Anti-Inflammatory Activity. J.I. 2017, 198, 3296-3306, https://doi.org/10.4049/jimmunol.1602059.

17. Li, K.; Li, Z.; Tao, Y.; Wang, Q.; Lai, Y.; Wu, W.; Peng, S.; Guo, Z.; Huang, H. Discovering Novel P38 $\alpha$ Inhibitors for the Treatment of Prostate Cancer through Virtual Screening Methods. Future Medicinal Chemistry 2019, 11, 3125-3137, https://doi.org/10.4155/fmc-2019-0223.

18. Michael, J.S.; Tamer, S.K.; Chunli, Y.; Kevin, N.D.; Pengyu, R. Computational Insights for the Discovery of Non-ATP Competitive Inhibitors of MAP Kinases. Current Pharmaceutical Design 2012, 18, 1173-1185.

19. Park, J. In Silico Screening and In Vitro Activity Measurement of Javamide Analogues as Potential P38 MAPK Inhibitors. IJMS 2017, 18, 2704, https://doi.org/10.3390/ijms18122704.

20. Lee, I.; Shin, Y.J. Machine Learning for Enterprises: Applications, Algorithm Selection, and Challenges. Business Horizons 2020, 63, 157-170, https://doi.org/10.1016/j.bushor.2019.10.005.

21. Thompson, N.C.; Greenewald, K.; Lee, K.; Manso, G.F. The Computational Limits of Deep Learning 2020, https://arXiv.org/2007.05558.

22. Saxe, A.; Nelli, S.; Summerfield, C. If Deep Learning Is the Answer, What Is the Question? Nat Rev Neurosci 2021, 22, 55-67, https://doi.org/10.1038/s41583-020-00395-8.

23. Echle, A.; Rindtorff, N.T.; Brinker, T.J.; Luedde, T.; Pearson, A.T.; Kather, J.N. Deep Learning in Cancer Pathology: A New Generation of Clinical Biomarkers. $B r \quad J$ Cancer 2021, 124, 686-696, https://doi.org/10.1038/s41416-020-01122-x.

24. Irwin, B.W.J.; Levell, J.R.; Whitehead, T.M.; Segall, M.D.; Conduit, G.J. Practical Applications of Deep Learning To Impute Heterogeneous Drug Discovery Data. J. Chem. Inf. Model. 2020, 60, 2848-2857, https://doi.org/10.1021/acs.jcim.0c00443.

25. Korkmaz, S. Deep Learning-Based Imbalanced Data Classification for Drug Discovery. J. Chem. Inf. Model. 2020, 60, 4180-4190, https://doi.org/10.1021/acs.jcim.9b01162.

26. Baskin, I.I. The Power of Deep Learning to Ligand-Based Novel Drug Discovery. Expert Opinion on Drug Discovery 2020, 15, 755-764, https://doi.org/10.1080/17460441.2020.1745183. 
27. Gupta, R.; Srivastava, D.; Sahu, M.; Tiwari, S.; Ambasta, R.K.; Kumar, P. Artificial Intelligence to Deep Learning: Machine Intelligence Approach for Drug Discovery. Mol Divers 2021, https://doi.org/10.1007/s11030021-10217-3.

28. Karim, M.R.; Beyan, O.; Zappa, A.; Costa, I.G.; Rebholz-Schuhmann, D.; Cochez, M.; Decker, S. Deep LearningBased Clustering Approaches for Bioinformatics. Briefings in Bioinformatics 2021, 22, 393-415, https://doi.org/10.1093/bib/bbz170.

29. Gütlein, M.; Kramer, S. Filtered Circular Fingerprints Improve Either Prediction or Runtime Performance While Retaining Interpretability. J Cheminform 2016, 8, 60, https://doi.org/10.1186/s13321-016-0173-z.

30. Nguyen, B.H.; Xue, B.; Zhang, M. A Survey on Swarm Intelligence Approaches to Feature Selection in Data Mining. Swarm and Evolutionary Computation 2020, 54, 100663, https://doi.org/10.1016/j.swevo.2020.100663.

31. Pagadala, N.S.; Syed, K.; Tuszynski, J. Software for Molecular Docking: A Review. Biophys Rev 2017, 9, 91102, https://doi.org/10.1007/s12551-016-0247-1.

32. Sardella, R.; Camaioni, E.; Macchiarulo, A.; Gioiello, A.; Marinozzi, M.; Carotti, A. Computational Studies in Enantioselective Liquid Chromatography: Forty Years of Evolution in Docking- and Molecular Dynamics-Based Simulations. TrAC Trends in Analytical Chemistry 2020, 122, 115703, https://doi.org/10.1016/j.trac.2019.115703.

33. Deeks, H.M.; Walters, R.K.; Barnoud, J.; Glowacki, D.R.; Mulholland, A.J. Interactive Molecular Dynamics in Virtual Reality Is an Effective Tool for Flexible Substrate and Inhibitor Docking to the SARS-CoV-2 Main Protease. J. Chem. Inf. Model. 2020, 60, 5803-5814, https://doi.org/10.1021/acs.jcim.0c01030.

34. Yadav, R.; Dhiman, U. Virtual Screening of Potential Drug Molecules Against Covid-19 Targets: A Drug Repurposing Approach. LIANBS 2022, 11, 2965-2980, https://doi.org/10.33263/LIANBS111.29652980.

35. PubChem Mitogen-Activated Protein Kinase 14 (Human) Available online: https://pubchem.ncbi.nlm.nih.gov/protein/Q16539 (accessed on 9 July 2021).

36. Wishart, D.S.; Feunang, Y.D.; Guo, A.C.; Lo, E.J.; Marcu, A.; Grant, J.R.; Sajed, T.; Johnson, D.; Li, C.; Sayeeda, Z.; et al. DrugBank 5.0: A Major Update to the DrugBank Database for 2018. Nucleic Acids Research 2018, 46, D1074-D1082, https://doi.org/10.1093/nar/gkx1037.

37. Online SMILES Translator Available online: https://cactus.nci.nih.gov/translate/ (accessed on 9 July 2021).

38. MOE, Molecular Operating Environment, 2019.01. (2020) Chemical Computing Group ULC, 1010 Sherbooke St. West, Suite \#910, Montreal, QC, Canada, H3A 2R7.

39. Witten, I.H.; Frank, E.; Hall, M.A. Data Mining: Practical Machine Learning Tools and Techniques; Morgan Kaufmann series in data management systems; 3rd ed.; Morgan Kaufmann: Burlington, MA 2011, ISBN 9780123748560.

40. Yap, C.W. PaDEL-Descriptor: An Open Source Software to Calculate Molecular Descriptors and Fingerprints. J. Comput. Chem. 2011, 32, 1466-1474, https://doi.org/10.1002/jcc.21707.

41. Abadi, M.; Agarwal, A.; Barham, P.; Brevdo, E.; Chen, Z.; Citro, C.; Corrado, G.S.; Davis, A.; Dean, J.; Devin, M.; et al. TensorFlow: Large-Scale Machine Learning on Heterogeneous Distributed Systems. https://arXiv.org/1603.04467 [cs] 2016.

42. Roeder, L. Lutzroeder/Netron 2021.

43. Bäuerle, A.; van Onzenoodt, C.; Ropinski, T. Net2Vis -- A Visual Grammar for Automatically Generating Publication-Tailored CNN Architecture Visualizations. IEEE Trans. Visual. Comput. Graphics 2021, 27, 29802991, https://doi.org/10.1109/TVCG.2021.3057483.

44. Caswell, T.A.; Droettboom, M.; Lee, A.; De Andrade, E.S.; Hunter, J.; Hoffmann, T.; Firing, E.; Klymak, J.; Stansby, D.; Varoquaux, N.; et al. Matplotlib/Matplotlib: REL: V3.4.2; Zenodo, 2021;

45. Waskom, M. Seaborn: Statistical Data Visualization. JOSS 2021, 6, 3021, https://doi.org/10.21105/joss.03021.

46. Hernandez, J.J.; Pryszlak, M.; Smith, L.; Yanchus, C.; Kurji, N.; Shahani, V.M.; Molinski, S.V. Giving Drugs a Second Chance: Overcoming Regulatory and Financial Hurdles in Repurposing Approved Drugs As Cancer Therapeutics. Front. Oncol. 2017, 7, 273, https://doi.org/10.3389/fonc.2017.00273.

47. Lavecchia, A. Deep Learning in Drug Discovery: Opportunities, Challenges and Future Prospects. Drug Discovery Today 2019, 24, 2017-2032, https://doi.org/10.1016/j.drudis.2019.07.006. 
48. Rogosnitzky, M.; Berkowitz, E.; Jadad, A.R. Delivering Benefits at Speed Through Real-World Repurposing of Off-Patent Drugs: The COVID-19 Pandemic as a Case in Point. JMIR Public Health Surveill 2020, 6, e19199, https://doi.org/10.2196/19199.

49. Zhang, Z.; Zhou, L.; Xie, N.; Nice, E.C.; Zhang, T.; Cui, Y.; Huang, C. Overcoming Cancer Therapeutic Bottleneck by Drug Repurposing. Sig Transduct Target Ther 2020, 5, 113, https://doi.org/10.1038/s41392-02000213-8.

50. Scannell, J.W.; Blanckley, A.; Boldon, H.; Warrington, B. Diagnosing the Decline in Pharmaceutical R\&D Efficiency. Nat Rev Drug Discov 2012, 11, 191-200, https://doi.org/10.1038/nrd3681.

51. Nwabufo, C.K. Introduction to the Mini Special Issue on next Generation Drug Discovery and Development: Rethinking Translational Pharmacology for Accelerated Drug Development. Drug Metabolism Reviews 2021, 53, 171-172, https://doi.org/10.1080/03602532.2021.1909614. 